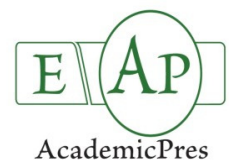

\title{
Differential Response of Bean (Phaseolus vulgaris L.) Roots and Leaves to Salinity in Soil and Hydroponic Culture
}

\author{
Duygu BAYRAM, Burcu SECKIN DINLER*, Eda TASCI
}

\author{
Sinop University, Department of Biology, Faculty of Art and Science, 57000, Sinop, Turkey; bseckin@sinop.edu.tr ("corresponding author)
}

\begin{abstract}
The present study aimed to investigate the response of common bean (Phaseolus vulgaris L. Volare) roots and leaves to salinity in different growth mediums (soil and hydroponic culture) through physiologic and biochemical analyses. The relative water content (RWC) and total chlorophyll (CHL) content decreased with $300 \mathrm{mM} \mathrm{NaCl}$ treatment in both cultures but did not change with $150 \mathrm{mM}$ treatment in soil culture. Similarly, the malondialdehyde (MDA) content did not change with 150 $\mathrm{mM}$ treatment in soil culture, whereas it increased in all other treatments. The highest increase in hydrogen peroxide $\left(\mathrm{H}_{2} \mathrm{O}_{2}\right)$ content was observed with $300 \mathrm{mM}$ treatment in hydroponic culture. The highest increase in superoxide dismutase (SOD) activity was observed in plant leaves in the hydroponic culture. Catalase (CAT) activity did not change with $150 \mathrm{mM}$ treatment in soil culture but decreased with $300 \mathrm{mM}$ treatment in both cultures. Ascorbate peroxidase (APX) activity decreased in all treatments, except in the roots in the hydroponic culture. The $\mathrm{Na}^{+}$and $\mathrm{Cl}^{-}$contents were higher in the hydroponic culture than in the soil culture. Salt stress induced more serious oxidative damage in the hydroponic culture compared to the soil culture.
\end{abstract}

Keywords: antioxidant enzymes, hydroponic, Phaseolus vulgaris, salt stress, soil

\section{Introduction}

Several environmental stress factors, such as air pollution, climate change, and drought, limit the crop yield and quality around the world. Salinity is also a significant stress factor that limits the plant growth and influences agricultural practices in various parts of the world (Afzal $e t$ al., 2006). The ever-increasing salinity problem has already affected $20 \%$ of irrigated land resources worldwide (Kader et al., 2008). Salt stress causes osmotic stress and ion toxicity in plants (Hasegawa et al., 2000). Osmotic stress starts after a threshold salt concentration around the roots is reached, leading to inhibition of water uptake and cell expansion, whereas ion toxicity starts with salt accumulation in the leaves, resulting in an increase in chlorosis and necrosis. In addition, salinity affects the photosynthesis rate (Sudhir and Murthy, 2004) because of decreased chlorophyll pigment and closure of stomata (Soussi et al., 1998; Bethke and Drew, 1992). The limitation of photosynthesis causes an over-reduction of photosynthetic electron chains and the production of reactive oxygen species (ROS), which are harmful to plant growth and development. These ROS, including superoxide radicals, hydrogen peroxide, and hydroxyl radicals, are highly reactive and can cause serious damage on membrane lipids, proteins, and nucleic acids. Salinity induces an oxidative stress in plant cells (Imlay, 2003). To protect the cells against oxidative damage, plants develop complex defense mechanisms, such as superoxide dismutase (SOD), catalase (CAT), ascorbate peroxidase
(APX), and glutathione reductase (GR) (Noctor and Foyer, 1998). The role of antioxidant enzymes in stress conditions has been well documented for many plant species (Bowler $e t$ al., 1992; Shalata et al., 2001; Sairam et al., 2005; Ashraf et al., 2008).

The common bean (Phaseolus vulgaris L.) is one of the most important grains for human nutrition. It is also a valuable leguminous crop worldwide because of its ability to fixate atmospheric nitrogen into the root nodules in a symbiotic interaction with soil rhizobia. This plant is classified as relatively more salt-sensitive compared with the other members of the legume family; more than $50 \%$ yield losses are experienced at soil salinities of over $2 \mathrm{dS} \mathrm{m}$ (Gama et al., 2007). Salinity also significantly reduces the growth of these species. Such salinity-induced impacts may result in changes in dry-matter allocation, ion relationships, water status, physiologic processes, biochemical reactions, or a combination of all these parameters (Khadri et al., 2001). The salt tolerance of glycophytes is believed to be related to their ability to avoid accumulating excess monovalent cations in their leaves while taking up $\mathrm{Cl}^{-}$ions (Lauter et al., 1988). High $\mathrm{Cl}^{-}$concentrations lead to nutritional imbalance and changes in water relations (Seeman et al., 1985; Gama et al., 2007).

Most of the studies previously conducted on salinity in crops were carried out in hydroponic systems, pots, or fields. Certainly, there are significant differences between the plants grown in each one of these systems. For instance, in soil experiments, the cation exchange mechanism affects soil 
features by changing the cation and anion activities. However, in hydroponic systems, the plants have to overcome the osmotic stress of the solution. Thus, it is important to elucidate the salt tolerances or responses of plants in different mediums. Although many studies have revealed the effects of salt stress on bean plants at different stages (Bayuelo-Jimenez et al., 2002; Esechie et al., 2002), there is no report in the literature about a comparative analysis of the changes in physiologic (growth and water content) and biochemical (chlorophyll content, antioxidant enzymes, and ion concentration) characteristics of the same bean plants exposed to salinity in different mediums (hydroponic and soil culture). Therefore, the present study aimed to investigate the response of common bean (Phaseolus vulgaris L. Volare) roots and leaves to salinity in different growth mediums (soil and hydroponic culture) through physiologic and biochemical analyses, compare the salt tolerance mechanisms of the plants in different mediums to obtain more tolerant cultivars, and underline the degrees of salinity-induced damage in different mediums.

\section{Materials and methods}

\section{Plant material and experimental design}

Common bean (Phaseolus vulgaris L.) seeds were obtained from a commercial seed company (Tasaco) in Antalya, Turkey. The seeds were sterilized in 5\% hypochloride solution for 10 minutes, rinsed three times with distilled sterile water, and then sown in plastic trays $(10 \times 14 \mathrm{~cm})$ filled with soil. After germination, seedlings were taken into a growth chamber at $25^{\circ} \mathrm{C}$ with $16 / 8 \mathrm{~h}$ day/night photoperiod and light intensity of $500 \mathrm{umol} \mathrm{m}^{-2} \mathrm{~s}$ ${ }^{-1}$. The seedlings were watered with Hoagland solution (Hoagland and Arnon, 1950). After 14 days of growth in the chamber, some of the plants were transferred to hydroponic culture. A week later, the seedlings were exposed to saline solutions of $150 \mathrm{mM} \mathrm{NaCl}$ and $300 \mathrm{mM}$ $\mathrm{NaCl}$. To reach the desired concentrations, $50 \mathrm{mM}$ was added to Hoagland solution once every $12 \mathrm{~h}$ for $48 \mathrm{~h}$ in both groups (hydroponic and soil culture). The plants were then harvested and stored at $-20^{\circ} \mathrm{C}$ until further analyses.

\section{Relative water content}

The relative water content (RWC) was calculated in accordance with Smart and Bingham (1974). The leaves were floated on deionized water for $5 \mathrm{~h}$ in low irradiance; then the turgid tissue was quickly blotted to remove excess water, and the turgid weights (TW) were determined. DW was determined after seedlings were dried in the oven at 70 ${ }^{\circ} \mathrm{C}$ for $72 \mathrm{~h}$.

\section{Chlorophyll content}

The chlorophyll contents of the leaves were measured in accordance with the method specified by Lichtenthaler and Wellburn (1983). The pigments from $0.1 \mathrm{~g}$ fresh leaves were extracted by using $80 \%$ acetone.

\section{$\mathrm{H}_{2} \mathrm{O}_{2}$ content}

The $\mathrm{H}_{2} \mathrm{O}_{2}$ content was determined according to Velikova et al. (2000). Fresh leaves $(0.1 \mathrm{~g})$ were homogenized in $5 \mathrm{ml}$ of $0.1 \%$ trichloroacetic acid (TCA) and centrifuged at $12,000 \mathrm{rpm}$ for 15 minutes. The supernatant $(0.5 \mathrm{ml})$ was then mixed with $0.5 \mathrm{ml}$ of buffer $(10 \mathrm{mM}$ potassium phosphate, $\mathrm{pH} 7)$ and $1 \mathrm{ml}$ of $1 \mathrm{M} \mathrm{KI}$. The absorbance reading was taken at $390 \mathrm{~nm}$.

\section{$\mathrm{Na}^{+}$and $\mathrm{Cl}^{-}$ion content}

The $\mathrm{Na}^{+}$content was determined by flame photometry according to Mathis (1956). The $\mathrm{Cl}^{-}$concentration was obtained by wet oxidation of dried leaf tissue with nitric and perchloric acids in accordance with the method adapted by Johnson and Ulrich (1959). The digest was diluted with 0.1 $\mathrm{N}$ perchloric acid, and $\mathrm{Cl}^{-}$concentrations were determined by atomic absorption spectrophotometry.

\section{Malondialdebyde content}

The level of lipid peroxidation in leaf samples was determined in terms of the malondialdehyde (MDA) content according to the method specified by Madhava Rao and Sresty (2000). The MDA content, an end product of lipid peroxidation, was determined by using the thiobarbituric acid reaction. The MDA concentration was calculated from the absorbance at $532 \mathrm{~nm}$, and measurements were corrected for nonspecific turbidity by subtracting the absorbance at $600 \mathrm{~nm}$. An extinction coefficient of $155 \mathrm{mM}^{-1} \mathrm{~cm}^{-1}$ was used to determine the MDA concentration.

For protein and enzyme extractions, $0.5 \mathrm{~g}$ of fresh leaf samples were homogenized in $1.5 \mathrm{ml}$ of $50 \mathrm{mM}$ sodium phosphate buffer $(\mathrm{pH} \quad 7.8)$ containing $1 \mathrm{mM}$ ethylenediaminetetraacetic acid (EDTA) $\mathrm{Na}_{2}$ and $2 \%(\mathrm{w} / \mathrm{v}$ ) polyvinylpolypyrrolidone (PVPP). All operations were done at $4^{\circ} \mathrm{C}$. Samples were centrifuged at $14000 \times \mathrm{g}$ for $30 \mathrm{~min}$, and supernatants were used to determine the protein content and enzyme activities. All spectrophotometric analyses were done on a UV-visible spectrophotometer.

\section{SOD activity}

The superoxide dismutase (EC 1.15.1.1) activity was assayed by its ability to inhibit the photochemical reduction of nitrotetrazolium blue chloride (NBT) at $560 \mathrm{~nm}$ (Beauchamp and Fridovich, 1973).

APX activity

The ascorbate peroxidase (EC 1.11.1.11) activity was measured according to Nakano and Asada (1981). The assay depended on the decrease in absorbance at $290 \mathrm{~nm}$ as ascorbate was oxidized. The reaction mixture contained 50 $\mathrm{mM}$ Na-phosphate buffer ( $\mathrm{pH} 7.0$ ), $50 \mathrm{mM}$ ascorbate, 0.1 mM EDTA Na, $1.2 \mathrm{mM} \mathrm{H}_{2} \mathrm{O}_{2}$, and $0.1 \mathrm{ml}$ of enzyme extract in a final assay volume of $1 \mathrm{ml}$. The concentration of oxidized ascorbate was calculated by using an extinction coefficient of $2.8 \mathrm{mM}^{-1} \mathrm{~cm}^{-1}$. One unit of APX was defined as $1 \mathrm{mmol} \mathrm{m} l^{-1}$ ascorbate oxidized $\mathrm{min}^{-1}$.

\section{CAT activity}

The catalase (EC 1.11.1.6) activity was assayed in a reaction mixture $(2 \mathrm{ml})$ containing $50 \mathrm{mM} \mathrm{K}$-phosphate buffer ( $\mathrm{pH}$ 7.0). Then, $12.2 \mathrm{mM} \mathrm{H}_{2} \mathrm{O}_{2}$ was added, and the reaction was started by adding $100 \mu \mathrm{l}$ supernatant. The activity was determined by monitoring the degradation of $\mathrm{H}_{2} \mathrm{O}_{2}$ at $240 \mathrm{~nm}$ over 2 min against a supernatant-free blank. Enzyme-specific activities were expressed as $\mu \mathrm{mol}$ of $\mathrm{H}_{2} \mathrm{O}_{2}$ oxidized $\mathrm{min}^{-1} \mathrm{mg}^{-1}$ protein (Bergmeyer, 1970). 


\section{Statistical analysis}

All data were subjected to analysis of variance, and the mean differences were compared by least significant difference (LSD) testing at $\mathrm{p}<0.05$ level. Each data point represented the mean of six replicates

\section{Results and discussion}

Salt and water stress are well known to limit the availability of water in tissues and to reduce the relative water content (RWC) in Phaseolus plants (Bayuelo-Jimenez et al., 2002; Kabir et al., 2004; Lazcano-Ferrat Lovatt, 1999). In the present study, compared with the control group in soil culture, the RWC did not change significantly in leaves with $150 \mathrm{mM} \mathrm{NaCl}$ treatment but decreased by $42.61 \%$ in hydroponic culture. In addition, $300 \mathrm{mM} \mathrm{NaCl}$ treatment inhibited the RWC by 31.30 and $58.47 \%$ in the soil and hydroponic cultures, respectively (Tab. 1). The decrease in RWC indicated a loss of turgor that resulted in limited water availability for the cell extension process, as also reported by Katerji et al. (1997). Besides, high exogenous salt concentrations lead to ion toxicity and osmotic stress damage in plant cells (Cuartero et al., 2006). It could be suggested that the decreased water content was related to osmotic stress in the leaves of Phaseolus vulgaris because, in the hydroponic culture, osmotic stress affected the roots by decreasing the water content in the nutrient solution directly and more negatively than in the soil culture at the same $\mathrm{NaCl}$ concentration $(300 \mathrm{mM} \mathrm{NaCl})$.

Stepien and Klobus (2006) reported strong evidence of salt effects on photosynthetic enzymes, chlorophylls, and carotenoids of plants. This is related to the interference of salt ions with the de novo synthesis of proteins and the structural component, rather than the breakdown, of chlorophyll (Jaleel et al., 2007). In the present study, compared with the control treatment, the total chlorophyll content did not change with $150 \mathrm{mM} \mathrm{NaCl}$ treatment in both the soil and hydroponic cultures, whereas it decreased by 50 and $26.30 \%$, respectively, with $300 \mathrm{mM} \mathrm{NaCl}$ treatment in the hydroponic and soil cultures (Tab. 1). Similarly, Gadallah (1999) showed that $\mathrm{NaCl}$ decreased the chlorophyll content in bean plants. However, Delfine $e t$ al. (1999) reported no changes in chlorophyll content over 20 days in salt-stressed spinach (Spinacia oleracea L.) plants.
Such findings agree with our current results. In the present study, the higher chlorophyll reduction rates in the hydroponic culture compared to the soil culture may be related to the higher $\mathrm{Na}^{+}$content in leaves with $300 \mathrm{mM}$ $\mathrm{NaCl}$ treatment.

Hydrogen peroxide $\left(\mathrm{H}_{2} \mathrm{O}_{2}\right)$ is a versatile molecule that may be involved in several cell processes in normal and stress conditions (Quan et al., 2008). In stress conditions, $\mathrm{H}_{2} \mathrm{O}_{2}$ is produced and accumulated, leading to oxidative stress in plants. Plants possess a battery of antioxidant mechanisms, both enzymatic and nonenzymatic, by which ROS are removed from the cells (Noctor and Foyer, 1998). In the present study, compared with the control treatment, the $\mathrm{H}_{2} \mathrm{O}_{2}$ content of roots and leaves increased by 5.7 and 5.4\%, respectively, with $150 \mathrm{mM} \mathrm{NaCl}$ treatment. Moreover, 300 $\mathrm{mM} \mathrm{NaCl}$ treatment increased the $\mathrm{H}_{2} \mathrm{O}_{2}$ content of roots and leaves by 39.12 and $48.93 \%$, respectively. In the hydroponic culture, $150 \mathrm{mM} \mathrm{NaCl}$ treatment increased the $\mathrm{H}_{2} \mathrm{O}_{2}$ content by $35.69 \%$ in roots and $21.56 \%$ in leaves. Treatment with $300 \mathrm{mM} \mathrm{NaCl}$ increased the $\mathrm{H}_{2} \mathrm{O}_{2}$ content by $71.59 \%$ in roots and $46.03 \%$ in leaves (Tab. 2). These findings are in agreement with the results of Sairam and Srivastava (2002). It can be suggested that the higher $\mathrm{H}_{2} \mathrm{O}_{2}$ content in roots with $300 \mathrm{mM} \mathrm{NaCl}$ treatment in the hydroponic culture may have led to more oxidative damage

Tab. 1. Changes in relative water content and total chlorophyll in leaves of Phaseolus vulgaris L. under salt stress for 48 hours in hydroponic and soil culture

\begin{tabular}{ccc}
\hline \multirow{2}{*}{ Hydroponic } & \multicolumn{2}{c}{ Leaves } \\
\cline { 2 - 3 } & $\begin{array}{c}\text { Relative water } \\
\text { content }(\%)\end{array}$ & $\begin{array}{c}\text { Total chlorophyll } \\
(\mathrm{mg} / \mathrm{g} \mathrm{FW})\end{array}$ \\
\hline $\mathrm{C}$ & $56.88 \pm 3.25^{\mathrm{a}}$ & $6.5 \pm 2.86^{\mathrm{a}}$ \\
150 & $32.51 \pm 2.67^{\mathrm{b}}$ & $6.1 \pm 2.14^{\mathrm{a}}$ \\
300 & $23.62 \pm 3.87^{\mathrm{c}}$ & $4.7 \pm 2.78^{\mathrm{b}}$ \\
Soil & & $7.8 \pm 3.14^{\mathrm{a}^{*}}$ \\
$\mathrm{C}$ & $84.27 \pm 2.98^{\mathrm{a}^{*}}$ & $6.9 \pm 2.18^{\mathrm{a}^{*}}$ \\
150 & $82.13 \pm .3 .89^{\mathrm{a}}$ & $3.9 \pm 1.67^{\mathrm{b}^{*}}$ \\
\hline 300 & $57.89 \pm 21.98^{\mathrm{b}^{*}}$ & \\
\hline
\end{tabular}

The different letters indicate a significant difference $(\mathrm{p}<0.05)(\mathrm{n}=6)$. C: control; $150 \mathrm{mM} \mathrm{NaCl} ; 300 \mathrm{mM} \mathrm{NaCl}$. *Indicates significant differences between the two mediums at the same concentrations

Tab. 2. Changes in malondialdehyde content and hydrogen peroxide in roots and leaves of Phaseolus vulgaris L. under salt stress for 48 hours in hydroponic and soil culture

\begin{tabular}{ccccc}
\hline \multirow{2}{*}{ Hydroponic } & \multicolumn{2}{c}{ Roots } & \multicolumn{2}{c}{ Leaves } \\
\cline { 2 - 5 } & Malondialdehyde $\left(\mathrm{nmol} \mathrm{gr} \mathrm{FW}{ }^{-1}\right)$ & Hydrogen peroxide $(\mu \mathrm{M} / \mathrm{gr})$ & Malondialdehyde $\left(\mathrm{nmol} \mathrm{gr} \mathrm{FW}^{-1}\right)$ & Hydrogen peroxide $(\mu \mathrm{M} / \mathrm{gr})$ \\
\hline C & $24.38 \pm 5.46^{\mathrm{a}}$ & $70.34 \pm 2.76^{\mathrm{a}}$ & $23.67 \pm 4.20^{\mathrm{a}}$ & $82.63 \pm 2.13^{\mathrm{a}}$ \\
150 & $32.78 \pm 4.98^{\mathrm{b}}$ & $95.45 \pm 1.68^{\mathrm{b}}$ & $36.12 \pm 3.29^{\mathrm{c}}$ & $100.45 \pm 1.19^{\mathrm{b}}$ \\
300 & $39.17 \pm 3.67^{\mathrm{c}}$ & $120.7 \pm 2.89^{\mathrm{c}}$ & $27.24 \pm 5.12^{\mathrm{b}}$ & $120.67 \pm 2.56^{\mathrm{c}}$ \\
Soil & & & & \\
C & $20.27 \pm 5.88^{\mathrm{a}^{\mathrm{b}}}$ & $72.36 \pm 2.56^{\mathrm{a}}$ & $21.41 \pm 3.29^{\mathrm{a}}$ & $80.35 \pm 2.78^{\mathrm{a}}$ \\
150 & $22.38 \pm 4.12^{\mathrm{a}}$ & $76.49 \pm 1.68^{\mathrm{b}}$ & $23.16 \pm 2.87^{\mathrm{a}}$ & $84.69 \pm 2.67^{\mathrm{b}^{\mathrm{a}}}$ \\
\hline 300 & $30.12 \pm 3.87^{\mathrm{b}}$ & $100.67 \pm 1.56^{\mathrm{c}}$ & $29.35 \pm 4.69^{\mathrm{b}}$ & $119.67 \pm 1.67^{\mathrm{c}}$ \\
\hline
\end{tabular}

The different letters indicate a significant difference $(\mathrm{p}<0.05)$ ( $\mathrm{n}=6)$. C: control; $150 \mathrm{mM} \mathrm{NaCl} ; 300 \mathrm{mM} \mathrm{NaCl}$. *Indicates significant differences between the two mediums at the same concentrations 
compared to the soil culture. Our results are also in good agreement with the findings of Mittova et al. (2004), who reported a decrease in hydrogen peroxide content in the roots of tomatoes.

Plants develop antioxidant enzymes, such as superoxide dismutase, peroxidase, catalase, ascorbate peroxidase, and glutathione reductase, to repair the damage to cellular components caused by reactive oxygen species (ROS), such as superoxide $\left(\mathrm{O}_{2}{ }^{-}\right)$, hydrogen peroxide $\left(\mathrm{H}_{2} \mathrm{O}_{2}\right)$, and hydroxyl radicals $(\mathrm{OH})$ (Noctor and Foyer, 1998). SOD plays a significant role in the removal of superoxide radicals from the compartments where they are formed (Alscher $e t$ al., 2002). In the present study, the SOD activity in the roots and leaves increased by 33.33 and $34.94 \%$, respectively, with $150 \mathrm{mM} \mathrm{NaCl}$ treatment in the soil culture. However, with $300 \mathrm{mM} \mathrm{NaCl}$ treatment, the SOD activity increased by $36.38 \%$ in roots and $36.11 \%$ in leaves. In the hydroponic culture, the SOD activity in the roots and leaves increased by 34.12 and $38.23 \%$, respectively, with $150 \mathrm{mM} \mathrm{NaCl}$ treatment, whereas with $300 \mathrm{mM} \mathrm{NaCl}$ treatment, the activity increased by $71.93 \%$ in leaves and $56.45 \%$ in roots (Fig. 1a and b). Parallel to the current findings, previous studies also reported increased SOD activities for cotton and tomato plants under salt stress

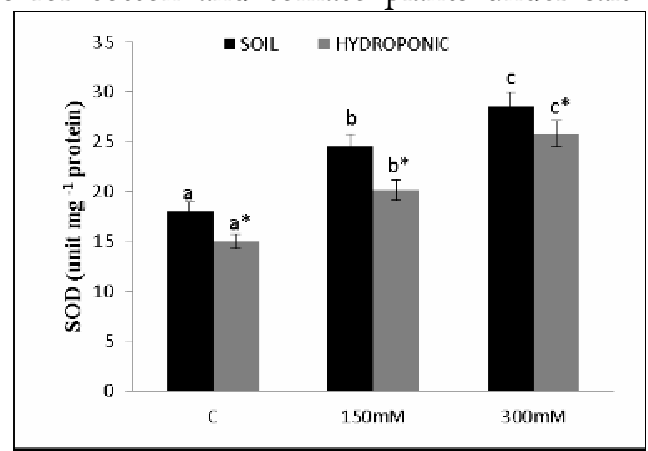

Fig. 1a. Changes in SOD activities in leaves of Phaseolus vulgaris $\mathrm{L}$. under salt stress for 48 hours in hydroponic and soil culture. The different letters indicate a significant difference ( $<<0.05)$. C: control; $150 \mathrm{mM} \mathrm{NaCl} ; 300 \mathrm{mM} \mathrm{NaCl}$. *Indicates significant differences between the two mediums at the same concentrations

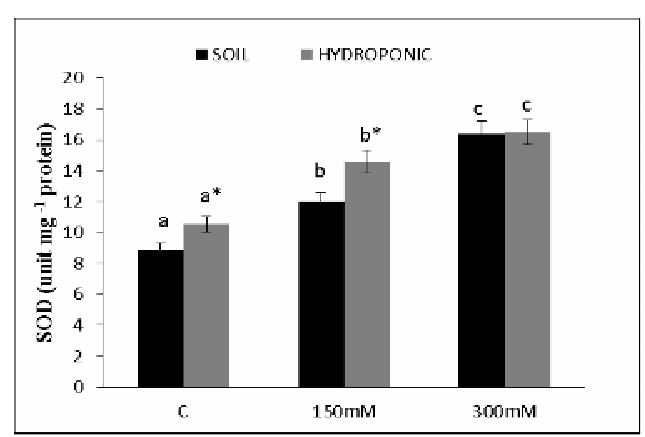

Fig. 1b. Changes in SOD activities in roots of Phaseolus vulgaris $\mathrm{L}$. under salt stress for 48 hours in hydroponic and soil culture. The different letters indicate a significant difference ( $\mathrm{p}$ < 0.05) C: control; $150 \mathrm{mM} \mathrm{NaCl} ; 300 \mathrm{mM} \mathrm{NaCl}$. *Indicates significant differences between the two mediums at the same concentrations
(Meloni et al., 2003; Mittova et al., 2001). It could be suggested that the oxidative damage was greater in the roots than in the leaves in terms of the unchanged SOD activity in both cultures with $300 \mathrm{mM} \mathrm{NaCl}$ treatment. However, there was a decrease in SOD activity in the hydroponic culture, which might have led to an induction of MDA content in roots and leaves in the soil culture.

In the present study, the CAT activity in the roots and leaves did not change with $150 \mathrm{mM} \mathrm{NaCl}$ treatment in the soil culture. However, it decreased by 39.21 and $27.69 \%$, respectively, in the leaves and roots with $300 \mathrm{mM} \mathrm{NaCl}$ treatment. These results are in agreement with the findings on the hydrogen peroxide content of the leaves and roots with $150 \mathrm{mM} \mathrm{NaCl}$ treatment. However, $300 \mathrm{mM} \mathrm{NaCl}$ treatment clearly increased the hydrogen peroxide content in the roots and leaves by 25.30 and $11.02 \%$, respectively, and decreased CAT activity (Fig. 2a and b). Similar decreases in CAT activity (Cavalcanti et al., 2004) and unchanged CAT activity (Azevedo Neto, 2005) under salt stress have been reported. Similarly to the soil culture, 150 $\mathrm{mM} \mathrm{NaCl}$ treatment increased the CAT activity by 21.56 and 56\%, respectively, in the leaves and roots in the hydroponic culture. Treatment with $300 \mathrm{mM} \mathrm{NaCl}$ decreased the CAT activity in the roots and leaves by 23.12

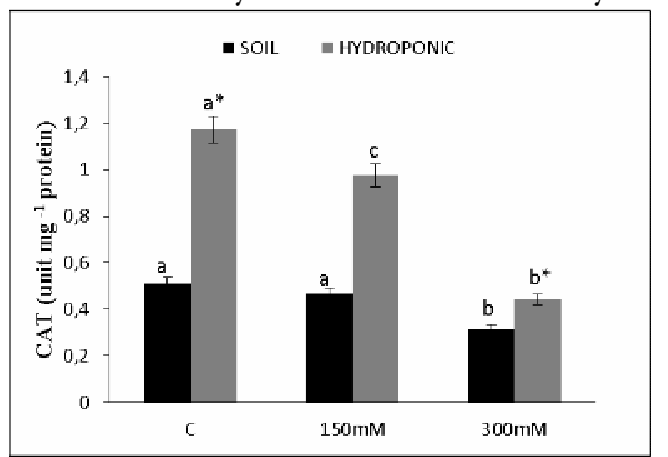

Fig. 2a. Changes in CAT activities in leaves of Phaseolus vulgaris $\mathrm{L}$. under salt stress for 48 hours in hydroponic and soil culture. The different letters indicate a significant difference $(p<0.05)$. C: control; $150 \mathrm{mM} \mathrm{NaCl} ; 300 \mathrm{mM} \mathrm{NaCl}$. *Indicates significant differences between the two mediums at the same concentrations

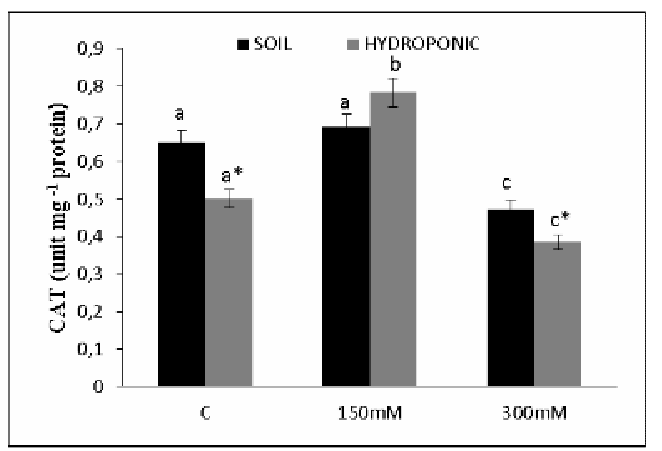

Fig. 2b. Changes in CAT activities in roots of Phaseolus vulgaris $\mathrm{L}$. under salt stress for 48 hours in hydroponic and soil culture. The different letters indicate a significant difference $(p<0.05)$. C: control; $150 \mathrm{mM} \mathrm{NaCl} ; 300 \mathrm{mM} \mathrm{NaCl}$. ${ }^{*}$ Indicates significant differences between the two mediums at the same concentrations 
223

and $62.39 \%$, respectively. Parallel to the current findings, Vaidyarathan et al. (2003) and Shalata et al. (2001) also reported increased CAT activities in rice and tomato plants under salt stress.

The predominant peroxidase enzyme is ascorbate peroxidase (APX; EC 1.11.1.11), which catalyzes the oxidation of ascorbate (AsA) by $\mathrm{H}_{2} \mathrm{O}_{2}$, generating dehydroascorbate radicals (Hideg, 1999). In the present study, compared with the control treatment, the APX activity in the leaves and roots increased by 53.60 and $76.92 \%$, respectively, with $150 \mathrm{mM} \mathrm{NaCl}$ treatment in the soil culture. The APX activity in the roots did not change with $300 \mathrm{mM} \mathrm{NaCl}$ treatment, but it increased by $45.36 \%$ in the leaves. In the hydroponic culture, $150 \mathrm{mM} \mathrm{NaCl}$ treatment did not change the APX activity in the leaves but

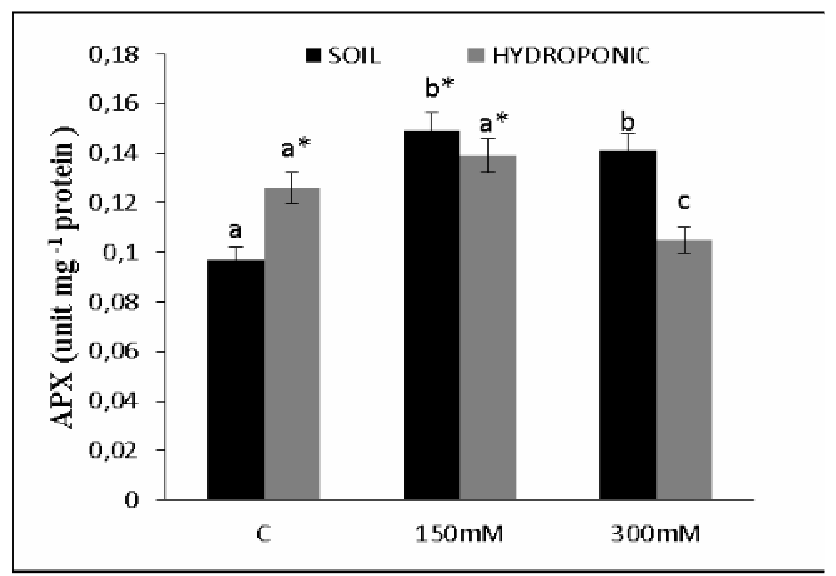

Fig. 3a. Changes in APX activities in leaves of Phaseolus vulgaris L. under salt stress for 48 hours in hydroponic and soil culture. The different letters indicate a significant difference $(p<0.05)$. C: control; $150 \mathrm{mM} \mathrm{NaCl} ; 300 \mathrm{mM} \mathrm{NaCl}$. *Indicates significant differences between the two mediums at the same concentrations

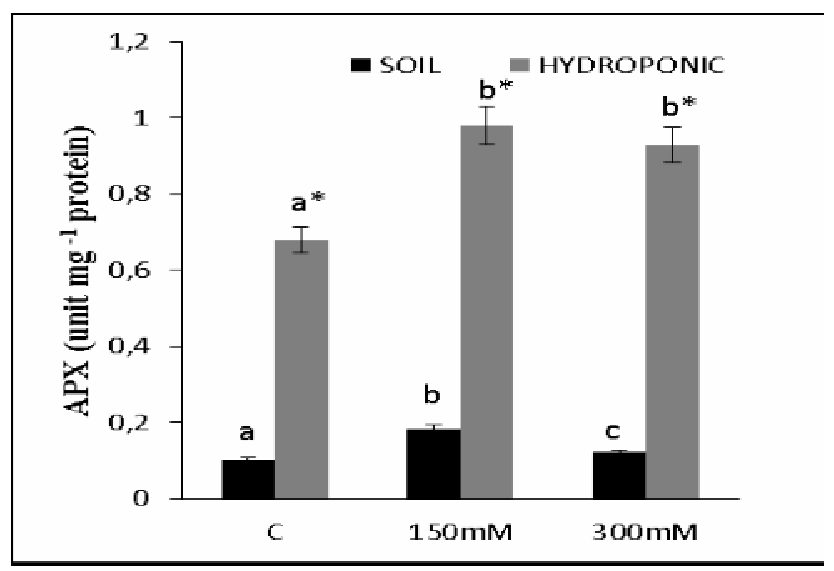

Fig. 3b. Changes in APX activities in roots of Phaseolus vulgaris $\mathrm{L}$. under salt stress for 48 hours in hydroponic and soil culture. The different letters indicate a significant difference $(\mathrm{p}<0.05)$. C: control; $150 \mathrm{mM} \mathrm{NaCl} ; 300 \mathrm{mM} \mathrm{NaCl}$. ${ }^{*}$ Indicates significant differences between the two mediums at the same concentrations increased that in the roots by $44.11 \%$. In addition, $300 \mathrm{mM}$ $\mathrm{NaCl}$ treatment increased the APX activity in the roots and leaves by 36.76 and $33.33 \%$, respectively (Fig. $3 a$ and b). Parallel to the current findings, the APX activity in peas and tomatoes reportedly increased under salt stress (Hernandez et al., 2000; Mittova et al., 2004), whereas it did not change in citrus plants under salinity (Arbona et al., 2003).

An increase in the level of MDA, produced during the peroxidation of membrane lipids, is often used as an indicator of oxidative damage. Many studies have reported that the lipid peroxidation levels (MDA) in plants under stress conditions are decreased by an effective antioxidant enzyme system. In the current results, compared with the control treatment, the MDA content in the leaves and roots did not change with $150 \mathrm{mM} \mathrm{NaCl}$ treatment in the soil culture but increased by 41.42 and $48.59 \%$, respectively, with $300 \mathrm{mM} \mathrm{NaCl}$ treatment. In the hydroponic culture, $150 \mathrm{mM} \mathrm{NaCl}$ treatment increased the MDA content by $24.41 \%$ in leaves and by $34.35 \%$ in roots. In comparison, the MDA content in the leaves and roots increased by 57.32 and $60.66 \%$, respectively, with $300 \mathrm{mM} \mathrm{NaCl}$ treatment. The highest increase was observed in the roots and leaves with $300 \mathrm{mM} \mathrm{NaCl}$ treatment in the hydroponic culture. The MDA content in mulberries and Phaseolus vulgaris has also been reported to increase under saline conditions (Sudhakar and Giridarakumar, 2001; Babu and Devaraj, 2008).

In the soil culture with $150 \mathrm{mM} \mathrm{NaCl}$ treatment, the increased APX activity was not efficient in terms of maintaining the hydrogen peroxide content (slight increase) in the leaves and roots because of the unchanged CAT activity. Besides, it could be suggested that the unchanged MDA content was related to the smaller increase in hydrogen peroxide caused by the increased SOD activity. The increase in APX activity with $300 \mathrm{mM} \mathrm{NaCl}$ treatment was also inefficient because the decrease in CAT activity might have led to an increase in hydrogen peroxide.

In the hydroponic culture, the increase in hydrogen peroxide with $150 \mathrm{mM} \mathrm{NaCl}$ treatment could be related to the decreased CAT activity. Similarly to the soil culture, the increase in APX activity was not sufficient to reduce hydrogen peroxide in the roots. However, at the same concentration, the unchanged CAT and APX activities clearly led to an increase in the hydrogen peroxide content in the leaves. The fact that $300 \mathrm{mM} \mathrm{NaCl}$ treatment increased the hydrogen peroxide content in leaves could be due to a decrease in CAT activity; similarly, the induction of APX activity was not enough to protect cells from oxidative damage.

In the present study, compared with the control treatment, the $\mathrm{Na}^{+}$content in the leaves increased 4.5- and 13.75 -fold with $150 \mathrm{mM}$ and $300 \mathrm{mM} \mathrm{NaCl}$ treatment, respectively. However, in the roots, the $\mathrm{Na}^{+}$content increased by $98.02 \%$ with $150 \mathrm{mM} \mathrm{NaCl}$ and 2.62 -fold with $300 \mathrm{mM} \mathrm{NaCl}$ treatment (Tab. 3). Glycophytic plants adapt to high salt concentrations by lowering their tissue osmotic potentials through an increase in inorganic ions from an external solution (Cacchorro et al., 1995). In Phaseolus species, the inorganic ions in leaves, especially $\mathrm{Cl}$, $\mathrm{Na}^{+}$, and $\mathrm{K}^{+}$, increase as the salt level increases. In the present study, the cultivated samples (Phaseolus vulgaris $\mathrm{L}$. Volare) accumulated $\mathrm{Na}^{+}$ions in their leaves, as also found 
Tab. 3. Changes in $\mathrm{Na}^{+}$and $\mathrm{Cl}^{-}$ion contents in roots and leaves of Phaseolus vulgaris $\mathrm{L}$. under salt stress for 48 hours in hydroponic and soil culture

\begin{tabular}{|c|c|c|c|c|}
\hline \multirow{2}{*}{ Hydroponic } & \multicolumn{2}{|c|}{ Roots } & \multicolumn{2}{|c|}{ Leaves } \\
\hline & $\mathrm{Na}^{+}(\%)$ & $\mathrm{Cl}^{-}(\%)$ & $\mathrm{Na}^{+}(\%)$ & $\mathrm{Cl}^{-}(\%)$ \\
\hline $\mathrm{C}$ & $0.33 \pm 4.21^{a}$ & $0.67 \pm 4.22^{\mathrm{a}}$ & $0.04 \pm 5.12^{\mathrm{a}}$ & $0.66 \pm 4.99^{a}$ \\
\hline 50 & $4.92 \pm 4.12^{b}$ & $3.95 \pm 4.09^{b}$ & $5.93 \pm 5.03^{b}$ & $7.01 \pm 4.32^{b}$ \\
\hline 300 & $11.76 \pm 3.97^{\mathrm{c}}$ & $11.46 \pm 4.32^{c}$ & $7.4 \pm 5.12^{c}$ & $8.7 \pm 4.81^{\mathrm{c}}$ \\
\hline \multicolumn{5}{|l|}{ Soil } \\
\hline $\mathrm{C}$ & $0.53 \pm 3.64^{a}$ & $1.01 \pm 4.35^{a^{*}}$ & $0.04 \pm 5.39^{\mathrm{a}}$ & $1.76 \pm 3.56^{\mathrm{a}^{*}}$ \\
\hline 150 & $1.05 \pm 3.12^{\mathrm{b}^{*}}$ & $0.95 \pm 4.23^{a}$ & $0.18 \pm 5.02^{a}$ & $1.54 \pm 3.12^{a}$ \\
\hline 300 & $1.39 \pm 3.65^{\mathrm{b}}$ & $0.96 \pm 4.12^{\mathrm{a}}$ & $0.55 \pm 4.99^{b}$ & $2.45 \pm 3.49^{b}$ \\
\hline
\end{tabular}

The different letters indicate a significant difference $\left(\mathrm{p}<0.05(\mathrm{n}=6)\right.$. C: control; $150 \mathrm{mM} \mathrm{NaCl} ; 300 \mathrm{mM}$ NaCl. ${ }^{*}$ Indicates significant differences between the two mediums at the same concentrations

by Bayuelo-Jimenez et al. (2002). In the hydroponic culture, compared with the control treatment, the $\mathrm{Na}^{+}$content in the leaves increased 14.82-fold with $150 \mathrm{mM} \mathrm{NaCl}$ and 18.5 -fold with $300 \mathrm{mM} \mathrm{NaCl}$ treatment. In the roots, compared with the control treatment, the $\mathrm{Na}^{+}$content increased 14.90- and 35.63-fold with $150 \mathrm{mM}$ and $300 \mathrm{mM}$ $\mathrm{NaCl}$ treatment, respectively. As a result, there were differences in ion accumulation between the hydroponic culture and the soil culture, as also found by Tavakkoli $e t$ al. (2010). The higher $\mathrm{Na}^{+}$and $\mathrm{Cl}^{-}$contents in the hydroponic culture, compared to the soil culture, may be related to the roots taking up minerals directly from the external solution more rapidly over $48 \mathrm{~h}$ and transmitting them to the leaves in response to salinity. In the soil culture, the soil matrix may have led to a decrease in the $\mathrm{Na}^{+}$content by ion exchange mechanisms. It can be suggested that the higher MDA content in the hydroponic culture compared to the soil culture is related to the toxic effects of accumulated $\mathrm{Na}^{+}$ ions.

In the soil culture, the $\mathrm{Cl}^{-}$content in the leaves increased by $12.3 \%$ with $150 \mathrm{mM} \mathrm{NaCl}$ treatment by $39.20 \%$ with $300 \mathrm{mM} \mathrm{NaCl}$ treatment. However, the $\mathrm{Cl}^{-}$content in the roots did not change with $150 \mathrm{mM} \mathrm{NaCl}$ and $300 \mathrm{mM}$ $\mathrm{NaCl}$ treatment. In the hydroponic culture, the $\mathrm{Cl}^{-}$content in the leaves increased 10.62 -fold with $150 \mathrm{mM} \mathrm{NaCl}$ and 13.18-fold with $300 \mathrm{mM} \mathrm{NaCl}$ treatment. In the roots, the $\mathrm{Cl}^{-}$content increased 5.89- and 17.10-fold with $150 \mathrm{mM}$ $\mathrm{NaCl}$ and $300 \mathrm{mM} \mathrm{NaCl}$ treatment, respectively (Tab. 3). The $\mathrm{Cl}^{-}$ions clearly increased to a greater extent in the hydroponic culture than in the soil culture. Dasgan and Koc (2009) and Tavakkoli et al. (2012) also reported that $\mathrm{Cl}^{-}$ ions increased in bean plants under salinity. Because both $\mathrm{Na}^{+}$and $\mathrm{Cl}^{-}$are toxic to plants, and $\mathrm{Na}^{+}$in particular causes the deterioration of the physical structure of soil, these ions are considered the most important (Dubey, 1997; Hasegawa et al., 2000). Unchanged $\mathrm{Cl}^{-}$ions in the roots can be related to the soil matrix, which leads to the cation exchange mechanism. The increase in $\mathrm{Cl}^{-}$was higher than that in $\mathrm{Na}^{+}$in all species, as also found by Bayuelo-Jimenez et al. (2002).

\section{Conclusions}

Based on the results of this study, it can be suggested that salt stress causes more oxidative damage in hydroponic culture than in soil culture. The changes in antioxidant enzyme responses in different mediums could be explained by a disturbance in the redox balance through the accumulation of toxic ions and osmotic stress, which was more rapid in the hydroponic culture.

\section{Acknowledgements}

The authors thank The Scientific and Technological Research Council of Turkey (TUBITAK) 2209 for its financial support.

\section{References}

Afzal I, Basra SMA, Farooq M, Nawaz A (2006). Alleviation of salinity stress in spring wheat by hormonal priming with $\mathrm{ABA}$, salicylic acid and ascorbic acid. Int J Agr Biol 8:23-28.

Alscher RG, Erturk N, Heath LS (2002). Role of superoxide dismutases (SODs) in controlling oxidative stress in plants. J Exp Bot 53:1331-1341.

Arbona V, Flors V, Jacas J, Garcia-Agustin P, Gomez-Cadenas A (2003). Enzymatic and non-enzymatic antioxidant responses of carrizo citrange, a salt-sensitive citrus roostoock, to different levels of salinity. Plant Cell Physiol 44:388-394.

Ashraf M, Athar HR, Harris PJC, Kwon TR (2008). Some prospective strategies for improving crop salt tolerance. Adv Agron 97:45-109.

Azevedo Neto AD, Prisco JT, Enéas-Filho J, Medeiros JR, GomesFilho E (2005). Hydrogen peroxide pre-treatment induces salt-stress acclimation in maize plants. J Plant Physiol 162:1114-1122.

Babu Nagesh R, Devaraj VR (2008). High temperature and salt stress response in french bean (Phaseolus vulgaris). Aust $\mathrm{J}$ Crop Sci 2(2):40-48.

Bayuelo-Jimenez JS, Jasso-Plata N, Ochoa I (2012). Growth and physiological responses of Phaseolus species to salinity stress. Int J Agr 80:207-222.

Beauchamp C, Fridovich I (1973). Isoenzymes of superoxide dismutase from wheat germ. Biochim Biophys Acta 317:50-64

Bergmeyer HU (1970). Methods of enzymatic analysis. Akademie Verlag, Berlin, Germany, 1: 36-647.

Bethke PC, Drew MC (1992). Stomatal and non-stomatal components to inhibition of photosynthesis in leaves of Capsicum annum during progressive exposure to $\mathrm{NaCl}$ 
225

salinity. Plant Physiol 99:219-226.

Bowler C, Montague MV, Inze D (1992). Superoxide dismutase and stress tolerance. Annu Rev Plant Physiol 43:83-116.

Cachorro P, Martinez R, Ortiz A, Cerda A (1995). Abscisic acid and osmotic relations in Phaseolus vulgaris L. under saline conditions. J Plant Growth Regul 14:99-104.

Cavalcanti FR, Oliveira JTA, Martins-Miranda AS, Viegas RA, Silveira JAG (2004). Superoxide dismutase, catalase and peroxidase activities do not confer protection against oxidative damage in salt-stressed cowpea leaves. New Phytol 163:563571.

Cuartero J, Bolarin MC, Asins MJ, Moreno V (2006). Increasing salt tolerance in the tomato. J Exp Bot 57(5):1045-1058.

Dasgan HY, Koc S (2009). Evaluation of salt tolerance in common bean genotypes by ion regulation and searching for screening parameters. J Food Agric and Environ 7:363-372.

Delfine S, Alvino A, Villani MC, Loreto F (1999). Restrictions to $\mathrm{CO}_{2}$ conductance and photosynthesis in spinach leaves recovering from salt stress. Plant Physiol 119:101-1106.

Dubey RS (1997). Handbook of photosynthesis, p. 859-975. In: Pessarakli M (Eds). Photosynthesis in plants under stressfull conditions, New York.

Esechie HA, Al-Saidi A, Al-Khanjari S (2002). Effect of sodium chloride salinity on seedling emergence in chickpea. J Agron Crop Sci 188:155-160.

Gadallah MAA (1999). Effects of proline and glycinebetaine on Vicia faba response to salt stress. Biol Plantarum 42:249-257.

Gama PBS, Inanana S, Tanaka K, Nakazaw R (2007). Physiological response of common bean (Phaseolus vulgaris L.) seedlings to salinity stress. Afr J Biotechnol 6:79-88.

Hasegawa PM, Bressan RA, Zhu JK, Bohnert HJ (2000). Plant cellular and molecular responses to high salinity. Annu Rev Plant 51:463-499.

Hernandez M, Fernandez-Garcia N, Diaz-Vivancos P, Olmos E (2010). A different role for hydrogen peroxide and the antioxidative system under short and long salt stress in Brassica oleracea roots. J Exp Bot 61:521-535.

Hideg E (1999). Handbook of plant and crop stress, p. 911-930, In: Pessarakli M (Eds), Free radical production in photosynthesis under stress conditions, New York.

Hoagland DR, Arnon DI (1950). The water culture method for growing plants without soil. Calif AES Bull 347:1-32.

Imlay JA (2003). Pathways of oxidative damage. Annu Rev Microbiol 57:395-418.

Jaleel CA, Manivannan P, Lakshmanan GMA (2007). $\mathrm{NaCl}$ as a physiological modulator of proline metabolism and antioxidant potential in Phyllanthus amarus. CR Biol 9330:806-813.

Johnson CM, Ulrich A (1959). II. Analytical methods for use in plant analysis. Calif AES Bull 766:30-33.

Kabir ME, Karim MA, Azad MAK (2004). Effect of potassium on salinity tolerance of mungbean (Vigna radiata L. wilczek). J Biol Sci 4:103-110.
Kader MA, Seidel T, Golldack D, Lindberg S (2006). Expressions of OsHKT1, OsHKT2, and OsHVA are differentially regulated under $\mathrm{NaCl}$ stress in salt-sensitive and salt-tolerant rice (Oryza sativa L.) cultivars. J Exp Bot 57:4257-4268.

Katerji N, Van Hoorn JW, Hamdy A, Mastrorilli MM, Karzel E (1997). Osmotic adjustment of sugar beets in response to soil salinity and its influence on stomatal conductance, growth and yield. Agr Water Manage 34:57-69.

Khadri M, Pliego L, Soussi M, Llcuh C, Ocana A (2001). Ammonium assimilation and ureide metabolism in common bean (Phaseolus vulgaris) nodules under salt stress. Agronomie 21:635-643.

Lauter DJ, Meiri A, Shuali M (1988). Isoosmotic regulation of cotton and peanut at saline concentrations of $\mathrm{K}$ and $\mathrm{Na}$. Plant Physiol 87:911-916.

Lazcano-Ferrat Lovatt CJ (1999). Relationship between relative water content, nitrogen pools, and growth of Phaseolus vulgaris L. and $P$. acutifolius a. gray during water deficit. Crop Sci 39:467-475.

Lichtenthaler HK, Wellburn AR (1983). Determinations of total carotenoids and chlorophylls $\mathrm{a}$ and $\mathrm{b}$ in leaf extracts in different solvents. Biochem Soc Trans 11:591-592.

Madhava RKV, Sresty TVS (2000). Antioxidative parameters in the seedlings of pigeon pea (Cajanus cajan L. millspaugh) in response to $\mathrm{Zn}$ and Ni stresses. Plant Sci 157:113-128.

Mathis WT (1956). Report on the flame photometric determination of potassium and sodium in plant tissue. $\mathrm{J}$ Assoc Off Analyt Chem Int 39:419.

Meloni DA, Oliva MA, Martinez CA, Cambraia J (2003). Photosynthesis and activity of superoxide dismutase, peroxidase and glutathione reductase in cotton under salt stress. Environ Exp Bot 49:69-76.

Mittova V, Tal M, Volokita M, Guy M (2002). Salt stress induces up-regulation of an efficient chloroplast antioxidant system in the salt-tolerant wild tomato species Lycopersicon pennellii but not in the cultivated species. Physiol Plant 115:393-400.

Mittova V, Guy M, Tal M, Volokita M (2004). Salinity upregulates the antioxidative system in root mitochondria and peroxisomes of the wild salt-tolerant tomato species Lycopersicon pennellii. J Exp Bot 55:1105-1113.

Nakano Y, Asada K (1981). Hydrogen peroxide is scavenged by ascorbate-specific peroxidase in spinach chloroplasts. Plant Cell Physiol 22:867-880.

Noctor G, Foyer CH (1998). Ascorbate and glutathione: keeping active oxygen under control. Annu Rev Plant 49:249-79.

Quan LJ, Zhang B, Shi WW, Li HY (2008). Hydrogen peroxide in plants: a versatile molecule of the reactive oxygen species network. J Integ Plant Biol 50:2-18.

Sairam RK, Roa KV, Srivastava GC (2002). Differential response of wheat genotypes to long term salinity stress in relation to oxidative stress, antioxidant activity and osmolyte concentration. Plant Sci 163:1037-1046.

Sairam RK, Srivastave GC, Agarwal S, Meena RC (2005). 
Differences in antioxidant activity in response to salinity stress in tolerant and susceptible wheat genotypes. Biol Plant 49:8591.

Seeman JR, Critchley C (1985). Effects of salt stress on the growth, ion content, stomatal behavior and photosynthetic capacity on a salt-sensitive species, Phaseolus vulgaris L. Planta 164:151-162.

Shalata A, Neuamann PM (2001). Exogenous ascorbic acid (Vitamin C) increases resistance to salt stress and reduces lipid peroxidation. J Exp Bot 52:2207-2211.

Smart RE, Bingham GE (1974). Rapid estimates of relative water content. Plant Physiol 53:258-260.

Soussi M, Ocana A, Lluch C (1998). Effects of salt stress on growth, photosynthesis and nitrogen fixation in chickpea (Cicer arietinum L.). J Exp Bot 49:1329-1337.

Stepien P, Klobus G (2006). Water relations and photosynthesis in Cucumis sativus L. leaves under salt stress. Biol Plant 50 (40):610-616.

Sudhakar C, Lakshmi A, Giridarakumar S (2001). Changes in the antioxidant enzyme efficacy in two high yielding genotypes of mulberry (Morus alba L.) under $\mathrm{NaCl}$ salinity. Plant Sci 161:613-619.

Sudhir P, Murthy SDS (2004). Effect of salt stress on basic processes of photosynthesis. Photosynthetica 42(4): 481-486

Tavakkoli E, Rengasamy P, Mcdonald GK (2010). The response of barley to salinity stress differs between hydroponics and soil systems. Funct Plant Biol 37:621-633.

Tavakkoli M, Poustini K, Alizadeh H (2012). Soluble proteins, a biochemical indicator for salinity screening in wheat cultivars (Triticum aestivum L.). Elixir Appl Botany 48:9312- 9314.

Vaidyanathan H, Sivakuma P, Chakrabarty R, Thomasm G (2003). Scavenging of reactive oxygen species in $\mathrm{NaCl}$-stressed rice (Oryza sativa L.)-differential response in salt-tolerant and sensitive varieties. Plant Sci 165:1411-1418.

Velikova V, Yordanov I, Edreva A (2000). Oxidative stress and some antioxidant system in acid rain treated bean plants: protective role of exogenous polyammines. Plant Sci 151:5966. 